See discussions, stats, and author profiles for this publication at: https://www.researchgate.net/publication/344653074

\title{
Letter to the Editor: Use of Direct Liver Stiffness Measurement in Evaluating the Severity of Liver Cirrhosis in Patients with Hepatocellular Carcinoma
}

Article in World Journal of Surgery · October 2020

DOI: 10.1007/s00268-020-05818-2

CITATIONS

0

2 authors:

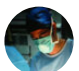

Antonio Pesce

Azienda Unità Sanitaria Locale Ferrara

88 PUBLICATIONS 458 CITATIONS

SEE PROFILE
READS

13

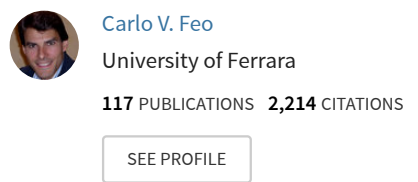

Some of the authors of this publication are also working on these related projects:

IMAGINE STUDY: Ileus MAnaGement INtErnational View project 


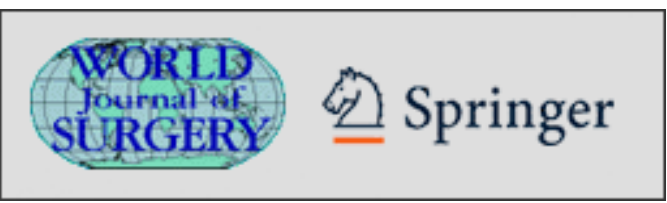

\section{Letter to the Editor: Use of Direct Liver Stiffness Measurement in Evaluating the Severity of Liver Cirrhosis in Patients with Hepatocellular Carcinoma.}

\begin{tabular}{|c|c|}
\hline Journal: & World Journal of Surgery \\
\hline Manuscript ID & WJS-20-08-2197 \\
\hline Manuscript Type: & Letter to the Editor \\
\hline $\begin{array}{r}\text { Date Submitted by the } \\
\text { Author: }\end{array}$ & 27-Aug-2020 \\
\hline Complete List of Authors: & $\begin{array}{l}\text { PESCE, ANTONIO; Ospedale del Delta } \\
\text { FEO, CARLO; Ospedale del Delta, Department of Morphology, Surgery } \\
\text { and Experimental Medicine, University of Ferrara, Ferrara, Italy. }\end{array}$ \\
\hline Keywords: & Hepatic, Liver \\
\hline
\end{tabular}




\title{
Letter to the Editor: Use of Direct Liver Stiffness Measurement in Evaluating the Severity of Liver Cirrhosis in Patients with Hepatocellular Carcinoma.
}

\author{
Authors: Antonio Pesce MD PhD ${ }^{1}$, Carlo Vittorio Feo MD FACS ${ }^{2}$. \\ ${ }^{1}$ Unit of General Surgery, Ospedale del Delta, Azienda USL di Ferrara, Ferrara, Italy. \\ ${ }^{2}$ Unit of General Surgery, Ospedale del Delta, Azienda USL di Ferrara \\ Department of Morphology, Surgery and Experimental Medicine, University of Ferrara, Ferrara, Italy.
}

Corresponding author: Antonio Pesce MD PhD

Adress: Via Valle Oppio, 2, 44023 Lagosanto (FE), Italy

Email: nino.fish@hotmail.it

Mobile : +393286680943 


\section{Dear Editor,}

We read with great interest the article by Gu J and co-workers [1] in which the authors have investigated the effective role of direct liver stiffness measurement in evaluating the severity of liver cirrhosis in patients with HCC undergone surgical resection. We would like to raise some interesting points.

In their study, the authors found the direct liver stiffness measurement more effective to pre-operative transient elastography in assessing the severity of hepatic cirrhosis in HCC patient, especially in moderate to severe cirrhosis with a sensitivity of $95.3 \%$ and $83.3 \%$, respectively. Regarding etiology, they only analyzed liver cirrhosis due to hepatitis B and C ; they don't show data about other etiologies, such as alcoholic or nonalcoholic steatohepatitis (NASH). Nowadays, the prevalence of these etiologies in Western countries is increasing rapidly. We wonder if the novel device could have the same sensitivity in assessing the severity of liver cirrhosis in these clinical settings.

In the discussion section of the manuscript the authors stated that, to date, transient elastography has not been used for evaluting the severity of liver cirrhosis in HCC patients scheduled for hepatectomy. Actually, in a previous study on 77 HCC patients [2] the pre-operative liver stiffness measurement was used to provide a better evaluation of portal hypertension and to predict surgical risk in resectable single HCC. Moreover, Kim et al. [3] reported liver stiffness measurement of $25.6 \mathrm{kPa}$ and a IGC R15 of $12 \%$ as the most accurate cut-off values for the prediction of post-operative hepatic failure.

An important point of weakness of this study is represented by the impossibility to perform a direct liver stiffness measurement in patients undergoing liver resection by laparoscopic or robotic approach. As evidenced from the literature, mini-invasive approaches in hepatic surgery are associated with a significant decrease in the incidence of post-operative ascites and liver failure [4]. This concept lies on the preservation of collateral circulation in the abdomen, reducing the damage to muscles and round ligament, which may contain important collateral vessels. 
Furthermore, the authors considered this new device very useful for a quick evaluation of the severity of liver cirrhosis, but we think that the extents of hepatectomy should be accurately evaluated before surgery and not intra-operatively, especially in HCC patients according to Barcelona Clinic Liver Cancer staging system [5].

\section{Finantial support and sponsorship.}

None.

\section{Conflicts of interest.}

There are no conflicts of interest to declare. 


\section{References}

1. Gu J, Zhang E, Liang B, et al (2020) Use of Direct Liver Stiffness Measurement in Evaluating the Severity of Liver Cirrhosis in Patients with Hepatocellular Carcinoma. World J Surg 44(8):2777-2783. doi:10.1007/s00268-020-05528-9.

2. Pesce A, Scilletta R, Branca A et al (2012) Does transient elastography (FibroScan ${ }^{\circledR}$ ) have a role in decision making in hepatocellular carcinoma? HPB (Oxford) 14: 403-8

3. Kim SU, Ahn SH, Park JY, et al (2008) Prediction of postoperative hepatic insufficiency by liver stiffness measurement (FibroScan((R))) before curative resection of hepatocellular carcinoma: a pilot study. Hepatol Int 2(4):471-477.

4. Levi Sandri GB, de Werra E, Mascianà G, et al (2016) Laparoscopic and robotic approach for hepatocellular carcinoma-state of the art. Hepatobiliary Surg Nutr 5(6):478-484.

5. Trovato MA, Pesce A, Sofia M et al (2013) Is BCLC algorithm useful in clinical practice? Study on 164 HCC patients. Hepatogastroenterology 60: 1742-5. 